\title{
Notes of guidance for College representatives on NHS advisory consultant and honorary consultant appointments committees in the UK
}

The College attaches great importance to the duties of its representatives on Advisory Appointments Committees as they play an important part in safeguarding the standards of psychiatric practice. The application of these guidelines is intended to raise standards of psychiatric practice and will allow some flexibility of interpretation for excellent candidates.

The representative of the College has two functions. The first is to ensure that the Committee is advised to exclude those candidates who do not meet the required standard. This can mean all candidates. The standards laid down by the Specialist Training Authority (STA) are set out below. The representatives of the College are asked to make sure that candidates applying for Consultant posts are on, or will be by the time they take up the post, the Specialist Register in the appropriate speciality or specialities. The second function is to assist in the selection of the most able candidate among those eligible who are judged to meet the particular requirements of the advertised post.

College representatives are entitled to receive copies of all applications for Consultant posts (as are all members of Advisory Appointments Committees), and are expected to take an active part in the short-listing procedures, which may be conducted by correspondence. They should also see a final short-list in good time for the meeting of the Committee, to satisfy themselves that no fully eligible candidate has been unreasonably excluded. If they believe that this has happened, they have the right to insist on a meeting of the Committee to review the short-list. Conversely, Assessors should make clear their objection to an unacceptable short-list of candidates, or individual candidates, whose qualifications and experience do not meet the College's criteria.

Because the role of an Appointments Committee is to recommend the candidate or candidates they consider suitable for the post, it is not appropriate for them to recommend a candidate who is not yet suitably qualified. With this in mind the College representative should remind the members of the Committee of the criteria laid down by the STA as to consultant posts in the relevant psychiatric specialities before the interviewing process commences. The members of the Committee should be courteously advised that candidates who are not already on the Specialist Register, or who are not likely to be by the time they take up the post, are ineligible for appointment. There is no objection to the Appointments Committee advising that a particular candidate, who is at present qualified for the post, would none the less benefit from particular further training before taking up his or her duties. This, for example, may apply in the case of a European candidate with no experience of the Mental Health Act or the NHS, or in the case of a super-specialist post for which at present no formal training is prescribed e.g. eating disorders.

College representatives are occasionally involved in Committees where questions of sexual or racial discrimination or health may arise. The following points should be noted:

(a) Employers in the UK and Republic of Ireland are required by law not to discriminate directly or indirectly on grounds of race, creed or sex against the employees or their candidates for employment. The College representative is expected to insist that this principle is at all times scrupulously observed during the proceedings of the Committee. The Equal Opportunities guidelines are available at the College in case of difficulty.

(b) Service on an Advisory Appointments Committee may possibly result in its members having to appear before a Tribunal in a race or sex discrimination case. It would be prudent for members to make, and keep in their own possession, notes about the candidates and the proceedings of the committee if such an appeal seems at all likely. If College Assessors are in any way concerned that there has been an irregularity in the proceedings of the Appointments Committee, they should warn the Committee that they would be notifying the President of the College and the Regional Adviser.

(c) It is not the task of the Appointments Committee to make a judgement on the physical or mental health of a candidate. If however, serious doubt regarding health does arise during the course of an interview, the College Assessor should apply the usual criteria of suitability and may 
wish to make a recommendation for appointment subject to satisfactory medical examination.

The College reminds its representatives that it attaches great importance to the criteria set out above. If it is not possible to resolve disagreement at the Appointments Committee itself, it is open to College representatives to send a minority report to the Chairman of the relevant employing Trust if, in the light of the above criteria, they are in disagreement with the recommendations of the Committee. The same action would be apposite if the representative should be concerned about some irregularity of composition or procedure of the Appointments Committee.

If any of these difficulties arise, the College representative should recommend very strongly that the Appointments Committee should either delay its recommendations or else submit them to the employing Trust without informing the candidates. If this is not done, the Assessor should ask that his/her disagreement be min- uted and, in the event of an appointment of a particular candidate proceeding to a vote, the College representative should vote against the appointment if the College's criteria have not been met.

If a candidate is appointed despite the objection of the College representative, that representative should telephone the College (Jane Hinton, extension 148) immediately after the meeting of the relevant Committee to notify the College of what has occurred and should forthwith submit a written summary specifying the reasons for the representative's objection to the appointment of the individual concerned. Prior to the conclusions of the Committee meeting the representative should tell the Appointments Committee what he/she proposes to do ${ }^{1}$.

The College Assessor, as other members of the Advisory Appointments Committee, should be prepared to counsel unsuccessful candidates.

College representatives are invited to keep the Registrar informed of any difficulty in interpreting these guidelines.

1. In Scotland National Panel Members are asked to apply these guidelines and in cases of difficulty should inform the Chairman of the Scottish Division before writing to the Secretary to the National Panel.

\section{Criteria for appointment to an NHS consultant post in psychiatry in the UK}

From 1 January 1997 it has been a legal requirement to be on the Specialist Register maintained by the General Medical Council (GMC) before taking up a substantive or honorary NHS consultant post. In order to be included in the GMC's Specialist Register a trainee must obtain a Certificate of Completion of Specialist Training (CCST) which is awarded by the Specialist Training Authority of the Medical Royal Colleges on the advice of the Royal College of Psychiatrists. In order to be recommended for the award of a CCST, the trainee should normally hold the MRCPsych or an equivalent qualification and have completed six years of training in psychiatry of which at least three years has been in the specialist registrar grade.
During higher training specialist registrars will be subject to annual appraisal involving the trainer, the scheme organiser and a representative of the local Postgraduate Dean's Office. If the final summative appraisal is satisfactory, the Royal College of Psychiatrists will be informed so the process leading to the award of a CCST can be triggered. Candidates may attend for interview at an Advisory Appointments Committee up to three months prior to completion of training but cannot take up post until they are on the Specialist Register.

Due weight should be attached to breadth of experience, participation in organised rotational schemes, periods spent abroad in relevant posts, and work in medical fields allied to psychiatry. The view of the College is that the responsibilities 